\title{
A MULHER E O CRIME
}

\author{
Napoleão L. Teixeira \\ Catedrático de Medicina Legal da Faculdade de \\ Direito da Universidade do Paraná.
}

Entrando no tema, eu perguntaria o que será, afinal de contas, a mulher? Seria necessário falar bem, ou seria preciso falar mal da mulher?

Tantos falaram bem! JULIO DANTAS, por exemplo, disse que "as mulheres bonitas não têm idade - como as estátuas". JORGE FERREIRA DE VASCONCELLOS disse que "todo fruto tem um bicho, e que o bicho dessa fruta, que é a mulher, é o homem". SALOMÃO definiu-a como "ânfora de flancos perfeitos que contém tôdas as delícias da existência". CHANFORT concluiu que "as mulheres tem uma célula a menos no cérebro e uma fibra a mais no coração". ALEXANDRE DUMAS, pai, disse que "é possível que os homens valham mais, mas não há dúvida de que as mulheres valem melhor". E há um provérbio árabe que ensina: "Cem homens podem fazer um acampamento, mas é bastante u'a mulher para fazer um lar".

Há, ao reverso, os que falaram mal. OSCAR WILDE, invertido sexual, disse que "a mulher é uma esfinge sem mistérios"; para êle, talvez fôsse... SCHOPENHAUER definiu a mulher como "um animal de cabelos compridos e de entendimento curto". PITIGRILLI disse não haver mulheres inteligentes: "são tôdas cretinas, diz êle; algumas, têm a agravante de parecerem inteligentes". Para JOLLIET, "as mulheres são relógios que constantemente se atrasam, a partir dos 25 anos". E VICTOR HUGO disse que "se a mulher odeia a serpente é, 
certamente, por rivalidade". EDSON num desabafo, escreveu: "quem inventou a primeira máquina de falar foi Deus, ao criar a mulher; eu inventei a segunda, mais aperfeiçoada, porque a minha faz-se parar quando se quer". PITIGRILLI ainda, diz que "o melhor excitante para u'a mulher é uma nota de mil..." Alguém disse "Há exceções"! Êle falou: "Sim, as que pretendem duas notas de mil"...

Há mulheres boas e há mulheres más. Não nos julgamos credenciado a falar mal da mulher. Acreditamos que aquêle que fala mal da mulher é porque, no fundo, a teme. $\mathrm{E}$ como não a tememos, ficaremos com os que não a denigrem...

Há mulheres lindas, há mulheres menos belas, mulheres feias e há mulheres feíssimas! VICTOR HUGO escreveu a respeito de mulheres grande, angulosas, carnudas, mulheres a que denominou femmes à soldat: nem são mulheres - disse êle "são verdadeiros homasses". As mesmas que, hoje, conhecemos como mari-machos, viragos, paraíbas...

$\mathrm{E}$ há as mulheres que chegam àquela "passagem da idade", em que mostram fios de barbas, e se lhes "abigodeia" o buço, e a voz se lhes engrossa, e o físico se agranda, quando, por fôrça do novo clima endocrínico, elas se virilizam e, dessas, o irreverente ANATOLE FRANCE diz estarem na "idade canônica".

Mas, é outro o tema do presente artigo. Voltemos ao assunto. Como tem sido encarada a mulher, através das legislações? No Direito Romano antigo, era considerada incapaz por toda a vida. Jamais considerada capaz para gerir sua pessoa e bens. No Direito Germânico primitivo, a mulher estava sempre sujeita a uma espécie de tutela: primeiramente, por parte dos pais; depois, por parte dos irmãos; finalmente, por parte do marido - e, a isso, chamava-se mundium. Foram elas sempre consideradas, nessas legislações, como menores, em face ao direito penal.

A mulher, primitivamente considerada "coisa", objeto de comércio, ascenderia, mais tarde, na Idade burgueza, à condi- 
ção de "indivíduo", e só com o evoluir da civilização, chegaria a ser considerada "pessoa". Tanto assim que houve quem exigisse a julgar a mulher, quando criminosa, tribunais femininos, porque - dizia-se - só mulheres são capazes de entender filigranas das psicologia feminina.

As leis romanas presumiam menor dólo no sexo feminino Segundo a Lex Julia, era ela passível de menor pena; daí, a célebre fórmula de FARINACIO: "...ed quaes sexus fragilitatem repecit".

Em nosso país, o Código do Império conferia à mulher o privilégio de não andar com calceta nos pés e de não ser enforcada, quando grávida. O Código de 1890, falava em "superioridade de sexos "no seu artigo $39, \S 5 .^{\circ}$, admitindo que quando 0 agente era do sexo masculino havia, sempre, uma superioridade de sexos. O Código de 1940 aboliu essa diferença, não considerando a mulher como inferior ao homem. Admite-lhe igual capacidade de responder pelos atos criminosos, só lhe abrindo exceção em duas circunstâncias: quando pune de maneira particularmente benigna o crime de infanticídio e o crime de abôrto, admitindo, implìcitamente, nestes dois casos, menor capacidade criminal na mulher.

Nos Estados Unidos, a imensa maioria das leis dos Estados da União, consideram a mulher fraca e inerme ante as artimanhas do homem. Qual a razão? Difícil explicar. Compreender-se-ia isso, em países em que a mulher fôsse considerada intelectual e socialmente inferior ao homem. Mas, não em U. S. A., onde - é fato sabido - as mulheres não são mães de família, mas, sim, pais de família... Tamanho o desprestígio, lá, do impròpriamente denominado sexo forte que - dizem nessa terra vem, em primeiro lugar, a criança; depois, a mulher; depois, o cão, e, por fim, o ...homem. Mas, que querem? As leis norte americanas, foram feitas por elas...

\section{DOS CRIMES FEMININOS}

Entendia LOMBROSO que a mulher não era menos cdiminosa que o homem e achava que a prostituição fôsse um equi- 
valente criminal feminino. $\mathrm{E}$, dessa conclusão apressada diz AFRÂNIO PEIXOTO - partiu êle para escrever mais um livro.

No entanto, sabe-se, hoje, que a prostituição não é um crime, nem um equivalente criminal feminino; que ela tem duas causas essenciais: uma, menor, biológica ou patológica; outra, maior, social ou econômica - que não nos cabe estudar aqui.

Há crimes de que a mulher tem o monopólio: os infanticídios, os abortos e os envenenamentos, para citar três exemplos mais importantes. Metade dos homicídios familiares lhes são atribuidos, e dêles tratamos, em detalhes, em nosso livro " $O$ SUICÍDIO".

A cleptomania seria outro delito frequente no sexo feminino: a compulsão a furtar seria quase que primitiva do sexo feminino; noventa por cento dos cleptômanos recrutar-se-iam entre as mulheres, e essa impulsão se acirraria nas proximidades da visita menstrual. Quem leu EÇA DE QUEIROZ deve recordar-se daquele conto "Singularidades de uma rapariga loira", em que êle retrata, à maravilha, uma cleptômana "au grand complet". Sugerimos a leitura do que escrevemos a respeito em nossa "PSICOLOGIA FORENSE E PSIQUIATRIA MÉDICO-LEGAL”, na parte relativa ao furto neurótico.

Crime por excelência da mulher: o envenenamento. Comum nas histéricas, carrega, em si o sêlo da histeria: é o crime estranho, dissimulado, misterioso, o crime praticado na sombra. Para um envenenador, assinala FREDERIC BOUTET, há cem envenenadoras. Diz PAUL BOURGET que o gesto de deitar a morte num copo é tìpicamente feminino: não exige fôrça física; não expõe quem o realiza a possível defesa da vítima, quando a arma branca ou a arma de fogo, manejadas por mãos frágeis, talvez falhassem. Daí a conclusão de autor francês, de que o veneno é a arma das mulheres e dos cobardes.

$\mathrm{E}$, dos venenos, o preferido pelas mulheres envenenadoras é, ainda, o arsênico. Por quê? Pela facilidade de sua aquisição, 
pelo sabor quase imperceptível, por sua côr fàcilmente disfarçável e, finalmente, porque o arsênico, ministrado em doses gradativas, paulatinas, pode passar quase despercebido àquele que o ingere. Envenenadoras famosas apareceram na história: Locusta, ao tempo de Nero; Lucrécia Borgia e sua famosa "acqua tofana"; Beatrice de Cenci; Catarina de Médicis; Madame de Montespan; a Marqueza de Brinvilliers; Catarina Voisin; e, recentemente, na França Marie Besnard, mulher que matou dois maridos, seu pai e sua mãi, o sôgro e a sogra, e mais seis parentes e amigos; descoberta, causou surprêsa a revelação de ser ela uma criminosa, por ser mulher notável por sua bondade, afabilidade, lhaneza de trato, por seu elevado espírito caritativo e por sua grande religiosidade.

Muitas vêzes, a mulher reveste o seu crime de crueldade. Então, ela lança mão do vitríolo - não só para agredir mas para prejudicar: não é só o ânimo de ferir; é, também, e principalmente, o ânimo de deformar. Quando não, essa crueldade assume aspectos de estarrecer: em nossa Capital, não faz muitos anos, uma "garçonette", ralada de ciumes, aproveitando-se da circunstância de o amante dormir de boca aberta, lançou-lhe pela garganta abaixo, um tóxico violento, evirizou-o a seguir e, depois, se matou. Há falar agora, nas passionais, ou rotuladas como tais. TRISTÃO DE ATAIDE, numa de suas crônicas, chamou atenção para o recrudescimento dos crimes passionais femininos. Demos-lhe a palavra: "Quando éramos estudantes, ríamos daquele conto de AFONSO ARINOS - "A Esteireira" - em que o autor descreve u'a amante enciumada que assassina a rival e bebe-lhe o sangue inda quente e fumegante". Reconhece, melancòlicamente, agora, que aquilo que, naquele tempo, parecia impossível, torna-se hoje, triste e dolorosa realidade.

De fato, multiplicam-se aquelas a que LEGOUVÉ chamou sublimes meurtrières, aquelas a que LEMAITRE denominou anges de l'assassinat.

As mulheres passionais comparecem, cada vez mais, e com frequência cada vez maior, no noticiário da imprensa; e essa 
imprensa deshonesta, essa imprensa "amarela", êsses jornais e revistas sensacionalistas, que fazem de crimes assim o prato predileto de um triste público leitor, público neurótico, ávido de lama, êsses jornais e revistas, são sem dúvida, os maiores responsáveis pela crescente e assustadora difusão dos crimes passionais.

Famoso, na antiguidade, o caso de Madame de Steinnheil, amante de Faure, que, na França, assassinou, bàrbaramente, seu espôso. Presa e julgada, a essa altura, já era ela uma heroína nacional, tanto a divinisara a imprensa. Quando do seu julgamento, o tribunal, as praças vizinhas, as ruas próximas, estavam apinhadas de povo. Absolvida (e não poderia deixar de o ser, em face daquele clima psicológico), foi uma verdadeira apoteose, tendo sido ela assediada, de imediato, por inúmeros e inflamados admiradores, que queriam casar-se com ela. Escolheu um lord inglês. 0 que, depois, aconteceu a êsse lord, é que a história não conta...

Houve entre nós, a famosa Aracy Abelha para não falar em outras. Aracy Abelha comete um crime. É endeusada pela imprensa. Seu nome é impresso; sua voz é irradiada; é televisionada; o país se transforma num vasto cenário de novela de rádio. Aracy Abelha é absolvida e tem onde escolher, se quiser, entre dezenas de homens, que, eom ela, querem se casar.

Aumenta sem dúvida, o número das maridicidas, de maneira impressionante. $\mathrm{E}$ é de surpreender o que vimos hoje, no noticiário dos jornais: uma delas havia sido condenada; uma dessas que abatem o marido a tiros, condenada! Sem dúvida alguma, deve ser muito feia porque, se fôsse bonita, temos absoluta certeza de que teria sido inevitàvelmente absolvida!...

Tratemos, agora, das adúlteras delinquentes. Discorrendo sôbre as adúlteras delinquentes, falou JIMENEZ DE ASÚA sôbre o porquê de usar-se a designação adúltera e não a denominação adúltero. Naturalmente, não poderíamos trazer novidade aqui e só com muito cuidado ousamos aflorar, de novo, o tema. 
Haveria um "direito" ao adultério? Haveria mesmo, nêste particular, o determinismo fisiológico, defendido por PIERRE LEROUX, GEORGE SAND e outros escritores? Haveria o "direito" de a mulher enganar seu marido? Diz GEORGE SAND que sim. A verdadeira GEORGE SAND, era u'a mulher intersexual, feia, magra, cabelos ralos e sem busto. Não a GEORGE SAND que vimos há tempos, no cinema. GEORGE SAND era mulher que vivia procurando amantes, que vivia à cata de sensações diferentes e, geralmente, com amantes efeminados. Pois GEORGE SAND escreveu que, quando a mulher não acha satisfação integral no casamento, tem o direito de procurar outro homem.

Defendendo êsse determinismo fisiológico, BALZAC, STENDHAL, ZOLA, MERIME, FLAUBERT, DUMAS e outros, acham que à mulher assiste o "direito" de enganar o marido, enquanto que, para outros, o adultério, affaire de canapé, "não é assunto que convenha ser discutido em sociedade".

Segundo PAUL BOURGET, os romances de STENDHAL são verdadeiras "Faculdades de Adultério": instilariam na alma dos jovens um veneno que jamais sairá, e êsse veneno é o do adultério.

Mas, o adultério, na nossa opinião, não é, de modo algum, um direito, nada havendo a justificá-lo. Somos dos que acredi tam no casamento. Há os que nêle não crêm: GUY DE MAƯ PASSANT, por exemplo, dizia que o casamento era uma "mistura de maus humores durante o dia e de maus odores durante a noite".

LAURINDO REBELO, boêmio carioca, disse que se o mar se casasse, por certo se amansaria. KEYSERLING diz que o casamento é um conflito; ao que HOLMES, completando, disse: Sim, o casamento é sempre, um conflito porque, nele, duas criaturas diferentes procuram viver juntas, em comum, buscando ajustar seus temperamentos, seus modos de sentir e de pensar. $\mathrm{E}$ isso jamais se processa sem conflitos. Mas, o que importa é que, dêsse conflito, redunde harmonia sexual e psicológica; Quando isso ocorre, podemos dizer que o casamento foi bem sucedido. 
Sugestivas, nêste particular, as palavras que FUSTEL DE COULANGES escreveu em "A Cidade Antiga”, a respeito do casamento: "Nuptiae sunt divini juris et humani communicatio". E, da mulher, disse êle: "Uxor socia humanae rei atque divinae". Assim é, realmente, a mulher; ou, pelo menos, assim deveria ela sempre ser: nossa companheira, não só nas coisas humanas, mas também nas coisas divinas.

Passemos ao estudo da mulher infanticida. 0 infanticídio é, entre nós, crime pouco frequente. Os que escreveram a respeito - NILTON SALES, no Rio de Janeiro; ESTÁCIO DE LIMA, na Bahia; ALMEIDA JÚNIOR, em São Paulo - compulsando as estatísticas, acham que, no Brasil, o infanticídio é de uma raridade extrema. Primeiro, porque muitos infanticídios passarão despercebidos; segundo, porque a mulher, em que pese a opinião dos que pensam de maneira contrária, é muito melhor do que nós, homens. A mulher é-nos superior em tudo: A mulher é-nos superior, em face da dor; a mulher é-nos superior, frente a qualquer sofrimento moral; a mulher é-nos superior, finalmente, no que diz respeito ao sexo. Nós homens, inscrevemos a vida no sexo; a mulher inscreve o sexo na vida. Para nós, o amor é um momento; para a mulher, o amor é uma existência inteira. $\mathrm{O}$ homem comparece no amor com o ato da posse, que é um impulso; a mulher comparece no amor com o organismo que nida o ovo, o organismo que gesta uma criança, o organismo que põe a criança ao mundo. A moça que, seduzida pelas palavras blandiciosas do homem, se lhe entrega, não o faz pelo desejo de conhecer um prazer novo, não o faz pela fome sexual. Nem, muito menos, pela curiosidade; ela vai a isso por amor, para atender aos reclamos daquele que, com tantas palavras belas, tudo lhe promete. 0 primeiro contacto sexual é, para a mulher, um traumatismo doloroso, desagradável. Ela não é, como o homem, o animal que vibra a cada contacto sexual: a mulher é a criatura para a qual o sexo é rigorosamente secundário. A lista de mulheres frígidas é enorme, imensa, sem fim. Se compulsarmos estatísticas, veremos que DUNCAN, em 200 mulheres, achou um têrço de mulheres frígidas; SPIVAK observou que, nas mulheres casadas por êle examinadas, apenas 35 a $40 \%$ conheciam o orgasmo sexual. KORGER e FRED con- 
cluiram que $75 \%$ das mulheres nada sentem, ou pouco sentem, na conjunção carnal. Diz-se que há raças "quentes" e que há raças "frias". E então a propaganda acha que as italianas são mulheres mais ardentes. Comparece o Professor Migliavacca, de Turim, com uma exaustiva estatística, demonstrando que $\mathbf{5 0 \%}$ das mulheres italianas são frígidas.

Das espanholas, não temos dados científicos, mas poderemos imaginar que elas não sejam tão frígidas, a acreditarmos na veracidade daquele decreto de Isabel de Aragão, citado por Afrânio, que recomendava às espanholas não exigissem dos seus parceiros "mais de oito contactos por dia". É, de fato, muito, muitíssimo mesmo!...

KINSEY, no seu famoso relatório, tão divulgado, acha que, nos Estados Unidos, apenas uma mulher em 10 seria fria, o que, a ser exato, viria revolucionar os achados de outros estudiosos. Diz KINSEY, que as mulheres norte-americanas não são tão frias, graças ao "petting" e ao "necking", que seriam carícias pré-nupciais: no "necking", teríamos o abraço e o beijo "qualitativo e quantitativamente impróprios"; no "petting", teríamos manobras mais avançadas, carícias sexuais marginais, sem entretanto, chegar à conjunção carnal. Segundo a gíria estudantil norte-americana, a diferença estaria na linha divisória: o primeiro (necking) estaria acima, e o segundo (petting) abaixo da linha do pescoço...

Em nosso meio paranaense, e de conformidade com observação pessoal, ratificamos a opinião expressa em nosso livro "PSICOLOGIA FORENSE E PSIQUIATRIA MÉDICO-LE$G A L$ " (capítulo "Transtornos do instinto sexual") - segundo a qual, a percentagem das mulheres frígidas ultrapassa, aquí, a casa dos $50 \%$.

Mas, voltando ao assunto, se consideramos a moça que se entrega a um homem e que engravida e que, depois, se vê largada, abandonada, desprezada, no ostracismo, lutando por manter a cabeça erguida, esforçando-se por ocultar o fruto do seu pecado, essa moça, quando chega ao parto e mata o filho "durante o 
parto ou logo após", e se torna infanticida - compreenderemos porque andou acertada a lei, punindo, de maneira benigna, a essa moça-mãe assassina.

Não há uma só grávida que tenha sua mente $100 \%$ perfeita durante a gestação. Há estudos sôbre isso: MAURICEAU, tocólogo francês, chamou, à gravidez, "maladie de neuf mois" (doença de nove mêses); tôdas as grávidas, diz FISCHER, apresentam perturbações mentais, mesmo aquelas casadas regularmente com tôdas as garantias, tranquilidade e segurança; e há um livro de MARCÉ em que êle descreve o estado mental das mulheres grávidas.

No momento em que dá à luz, mesmo normalmente, diz JUERG, nenhuma parturiente tem perfeito seu estado mental: do têrço para o fim do trabalho de parto, não é mais senhora de sua mente, não é mais dona do seu psiquismo. Compreende-se, portanto, que, se a criatura normal é assim, como não será com aquela que, carregando, dentro de si, o pêso de gravidez culposa, culmina no crime? Eis porque nosso Código penal, tão evoluído - talvez o terceiro do mundo, diz o Prof. JIMÉNEZ DE ASÚA (primeiro o peruano; segundo o uruguaio; terceiro o nosso) - encara com benevolência a mulher infanticida, considerando seu crime um "delictum exceptum", punindo-o de maneira suave. Em "Canaã”, de Graça Aranha, vamos encontrar um exemplo, calcado em fato que realmente aconteceu. Se algum dos senhores se perder, um dia, no hinterland espírito-santense poderá encontrar o processo de Maria, a infanticida, e ler até a sentença prolatada pelo mesmo Graça Aranha, nessa época, Juíz de localidade do interior $\left({ }^{*}\right)$.

Em GOETHE, no "Fausto", os senhores vão encontrar mais um exemplo de infanticídio, cometido por Margarida. A loira Margarida, depois que pertenceu ao Fausto rejuvenescido,

(*) O fato passou-se em Santa Leopoldina (Estado do Espírito-Santo), onde Graça Aranha era juíz municipal. Coube a êste prolatar a sentença, condenando Maria; mais tarde, a então Côrte de Justiça, de Vitória, modificou-lhe a sentença, absolvendo-a. 
vê as calamidades desabarem sôbre sua casa: seu irmão, tomba em duelo com o próprio Fausto, ferido pela espada de Mefistófeles; sua mãi, morre, vítima de um êrro da própria Margarida e o filho desta, fruto do seu amor pecaminoso, é por ela mesma afogado, ao nascer. Mas, Margarida salva-se: embora condenada pela justiça dos homens, é rehabilitada pela justiça celeste. Ascende aos céus, onde se transforma em "A Penitente"; e é ela quem, no céu, intercede pelo perdão de F'austo. Intercede junto à "Mater Gloriosa", por intermédio de três pecadoras famosas: "Magna Peccatrix", que foi Maria Madalena, aquela a quem Jesus perdoou porque muito amou; a "Mulier Samaritana", que foi aquela Samaritana que, na fonte de Jacob, em Sichen, deu de beber a Jesus, tendo-lhe então Jesus prometido a água que aplacaria a sêde eterna. E finalmente, a terceira pecadora famosa, que intercede junto à "Mater Gloriosa" pelo perdão de Fausto, é "Maria Aegiptiaca", prostituta famosa em Jerusalém, que, depois de muitos anos de vida dissoluta e pecaminosa, foi tocada pela graça divina. viveu 40 anos no deserto, alçando-se, por fim, à santidade.

Escreve Mellusi, em sua bela obra" "Delinquenti dell'Amore": "Se Margherita può, dopo la sua condanna in terra, essere assunta in cielo, accanto alla Mater Gloriosa, pienamente riabilitata, e riabilitadta a tal punto, da potere intercedere con fortuna anche per il suo amante, vuol dire che in cielo non si ha per il infanticidio tutto l'orrore che si ha sulla terra, o che, per lo meno, si dà ai moventi del delitto una valutazione diversa da quella che dà la morale sociale".

Voltando ao tema crime - por que vai a mulher ao crime?

Dizem os freudistas que é pelo penisneid: tôda mulher se consideraria uma criança castrada e, vida em fora, lutaria pela conquista disso que o homem tem e ela não: um falus. Seria êsse penisneid, essa "inveja do penis", que a levaria a querer equiparar-se ao homem, a querer-se-lhe igualar, cortando o cabelo curto, adotando vestes parecidas, frequentando Universidades, fazendo concursos, ombreando-se com êle nos empregos, 
nas fábricas, nos exércitos, etc.. Seria também isso que a levaria ao crime. É uma hipótese engenhosa, que não convence.

PORTO-CARRERO, descreve a mulher como devendo ser a guardiã do lar; aquela que deveria ficar em casa, junto à roca, tecendo as vestes dos seus; cosinhando o alimento; olhando pelos filhos, enquanto o marido, lá fora, trabalha e guerreia. Mas, diz êle: o mundo progrediu; as grandes indústrias tornaram inútil à mulher cardar a lã ou tecer o linho; o "jardim da infância" tornou desnecessário à mulher cuidar do filhinho, a partir de certa idade; as restrições à natalidade diminuiram também à mulher o número de filhos. Então, a mulher, não tendo o que fazer em casa, atirou-se a vida, lá fora; passou a viver nas rodas de jôgo e de clubes; transformou-se no "mamífero de luxo", na criatura fútil, indolente, viciosa, na medula ávida de espasmos. É a mulher que não tendo (ou não querendo ter...) o que fazer, no lar, gasta seus ócios, intoxicando-se com bebidas e entorpecentes; empeçonhando-se com a má literatura, o máu cinema, o máu teatro, e máu rádio e a péssima televisão; que julga chic o adultério; que... - mas, isso seria um nunca mais acabar! É a mulher que vai ao crime! É outra hipótese, melhor que a precedente.

Fala GILBERTO FREYRE, da "compressão social" da mulher. A mulher seria uma criatura eternamente reprimida e, por isso, na sua revolta, iria ao crime. Outra explicação, pouco convincente.

Nada disso é verdade. A mulher só vai ao crime por fôrça da sua tragédia biológica. MICHELET falou que a mulher é uma "eternelle blessée". Critura que sofre desde o nascimento, até à hora da morte. Daí haver HIPóCRATES dito que a vida da mulher é uma contínua enfermidade. Basta que vejamos isso:

Mal adolesce, vem a menstruação; não há alguma da qual se possa dizer que tenha seu psiquismo $100 \%$ durante a menstruação. COUTTS, estudando as sentenciadas existentes na penitenciária de VALPARAÍSO, achou que 90\% delas haviam 
praticado o crime na vigência do estado menstrual. SCHICHAROW e NEMILOW chegaram a conclusões idênticas. E BUGALLO-SANCHEZ defendeu, num livro, a tese da "responsabilidade atenuada da delinquente menstruante".

Viria, depois, a gravidez e, da gravidez, dissemos há pouco que, uns, a catalogam como "doença de nove mêses" (Mauriceau), ao passo que André Maurois a conceitua como "pesadêlo de 9 mêses". Viria o parto, êsse traumatismo gigantesco. Viria a lactação. E a luta com os filhos.

Viria, finalmente, quando a vida pende para o ocaso, a menopausa. Quando o homem se sente no apogeu, no ápice, lá no alto, quando se afirma, trabalha e vence, a mulher envelhece. Quando o homem ultrapassa os 45 anos, está, normalmente, cheio de pujança, produzindo, realizando - a mulher está na descida. Seu lar é um ninho vasio: os filhos já se foram, ou estão partindo. 0 marido, sabe-se, máu enfermeiro. A espôsa enfêrma, que já perdeu seus encantos, não mais é a companheira desejável. Então êle, que se aquece aos derradeiros calores do "sol de outono", cheio de verdores e "fogos" novos (mas, que não durarão muito), êle anda à cata de conquistas fáceis. É isso um espinho a mais na alma da mulher. Compreende-se porque, então, a mulher, na menopausa, compareça tanto na criminalidade. Quando não vai ao crime, vai muitas vêses, ao frenocômio, pois sua psíque, não raro, baqueia.

A mulher delinquiria mais ou menos do que os homens? Para cada cem homens sentenciados, dizem as estatísticas, têm ido ao cárcere:

\begin{tabular}{|c|c|c|}
\hline \multicolumn{2}{|c|}{3 mulheres } & (Japão, Índia e América do Sul) \\
\hline 10 & " & (América do Norte) \\
\hline 14 & " & (França) \\
\hline 16 & " & (Itália) \\
\hline 23 & " & (Alemanha) \\
\hline 24 & " & (Inglaterra) \\
\hline 27 & " & (Áustria) \\
\hline 38 & " & (Dinamarca). \\
\hline
\end{tabular}


Entre nós, no Brasil, a última estatística revelou que entre 4.633 sentenciados, 4.287 eram homens, 300 menores e apenas 46 mulheres.

À luz das estatísticas, a mulher delinquiria menos, pois.

Seria isso exato? Não, não é exato. As estatísticas dão êsses dados, mas se esquecem-frequentemente de que, como disse PASCALE, muitos crimes são desconhecidos da mulher.

Ao reverso, a maioria dos crimes que a mulher comete ficam ignorados, particularmente abortos, infanticídios e homicídios familiares. $\mathrm{E}$ há também a benignidade do júri: o júri condena apenas uma mulher em cada dez.

Outra razão por que a mulher compareceria com menos frequência nas estatísticas criminais: ela enfrenta um conflito pela vida menos áspero que nós. É cá fora, na rua, na profissão, na nossa atividade, que os conflitos se criam e aparecem. É cá fora que, frequentemente, somos levados ao crime. Por isso é que a mulher, por fôrça da sua situação, ainda relativamente afastada da luta, iria menos ao crime do que nós.

Tanto assim que o número de criminosas aumenta, nos países em que a mulher participa da luta, em pé de igualdade com os homens (Alimena).

Terminemos, recordando que muitos indivíduos, antes de levarem a efeito seus crimes, costumam ir à ...igreja, afim de pedirem a ajuda dos céus para o bom êxito de sua emprêzas criminosas. Alguns, chegam mesmo a fazer promessas. Isso, que ocorre com homens, não é raro no que diz respeito às mulheres que, algumas vezes, recorrem às mais estranhas súplicas; como aquela camponêsa, de que nos fala a irreverência de ANATOLE FRANCE, que, genuflexa e contrita, implorava deante do altar: "ó Virgem Santa, tú que concebeste sem pecar, permití-me a mim pecar sem conceber!"

Sim, é, de fato, u'a monstruosa heresia que nós, religiosos, repetimos com o mais sagrado dos horrores, mas que, infelizmente, retrata, com fidelidade, o triste psiquismo dessas pobres criaturas. 